\title{
Instituições Financeiras Internacionais Ligadas à ONU
}

Sebastião de Sant'Anna e Silva

Professor universitário (UFRJ)

dúvid É sempre oportuno e construtivo realçar a contribuição sem curso relevante da Organização das Nações Unidas, após o delhoria do primeiro quarto de século de sua existência, para a methoria do padrão de vida dos povos da Terra e estimular o intercâmbio de riquezas entre as Nações. Se têm sido menores do que os esperados os resultados dos esforços da ONU em prol da paz e do entendimento político entre as Nações, menos por culpa da Organização do que pelo egoísmo e cobiça que ainda ditam as normas da política internacional, grandes têm sido os frutos colhidos nos setores que serão abordados neste artigo. Nós nos incluímos entre os que acreditam e confiam na ONU e fazem justiça aos seus esforços em favor da paz e do entendimento entre as Nações. Apesar dos conflitos armados que, infelizmente, ainda ensangüentam e cobrem de luto o planeta, deve-se em grande parte à ONU o ter conseguido a localização das operações militares, evitado sua generalização ou sua temida transformação em confronto direto entre as grandes potências que detêm os terriveis en. genhos de destruição, capazes de por em risco a própria existên. cia do nosso planeta. Damos graças a Deus pelo fato de ainda existir uma Assembléia internacional aberta e de livre debate, onde é possível substituir o entrechoque das armas pelo duelo oratório, por mais aceso que seja este último, e onde existe uma tribuna livre na qual é possível fazer ouvir os protestos das na. çôes fracas vitimadas pela injustiça e pela prepotência dos Estados poderosos.

Além do mais, se é justificável uma atitude de pessimismo e de negação, quando o clamor de uma Tchecoslováquia violen. tada é silenciado pela conveniência ou pelo acordo tácito dos que 
se consideram os grandes do mundo, não é menos justificável uma posição de otimismo e de fé quando são computados os resultados positivos alcançados no campo da assistência técnica, do amparo ao desenvolvimento das áreas atrasadas e da promoção do livre intercâmbio de mercadorias, capitais e "know-how" entre as Nações.

A justificação da intervenção da ONU nos setores econômicos e financeiros encontra-se no preâmbulo da Carta das $\mathrm{Na}$. ções Unidas, promulgada na Cidade de São Francisco aos 26 de junho de 1945. Nesse preâmbulo, entre os grandes objetivos da Organização, figurou expressamente o de "promover o progresso social e melhores condições de vida dentro de maior liberdade" assim como o de "empregar os instrumentos internacionais para a promoção do progresso econômico e social de todos oṣ povos."

A declaração genérica desses objetivos, no preâmbulo da Carta das Nações Unidas, foi especificada no artigo $1 .^{\circ}$ do Capítulo I da mesma Carta, no qual se incluiu, entre as finalidades das $\mathrm{Na}$. ções Unidas: "Conseguir a cooperação internacional na solução de problemas internacionais de caráter econômico, social, cultu. ral ou humanitário, e promover e encorajar o respeito pelos direitos humanos e pelas liberdades fundamentais de todos, sem distínção de raças, sexo, linguagem ou religião."

$\mathrm{Na}$ estruturação dos órgãos da ONU, a Carta de São Fran. cisco procurou equipá-la para a consecução de seus objetivos no campo econômico e social. Foram assim estabelecidos, como os seus principais órgãos : a Assembléia Geral, o Conselho de Segu. rança, o Conselho de Mandatos, a Corte Internacional de Justiça e o Secretariado.

Ao Conselho Econômico e Social, constituído por 27 mem. bros das Nações Unidas eleitos pela Assembléia Geral, atribuiu a Carta de São Francisco as funções de "preparar ou iniciar estudos e relatórios referentes à economia internacional e a assuntos de natureza social, cultural, educacional, sanitária e correlatos, assim como fazer recomendações com relação a qualquer desses assuntos à Assembléia Geral, aos países-membros das Nações Unidas e às agências especializadas respectivas". O Capítulo X da Carta formulou, não só a competência do Conselho Econômico e Social, seus métodos de ação, suas ligações com a Assembléia Geral e sua composição, como também estipulou o modo de sua colaboração com as agências especializadas e organizações não governamentais. Merece destaque a incumbência dada ao Conselho para "instituir comissões no campo econômico e social e para 
a promoção dos direitos humanos, assim como outras tornadas necessárias para o desempenho de suas funções". Quatro Comissões regionais foram até hoje instituídas pelo Conselho Econômico e Social : para a Europa, para a Asia e o Extremo Oriente, para a América Latina e para a Africa. Essas comissões regionais, integradas por especialistas de alto nível e encarregadas de examinar problemas econômicos específicos das regiões em que atuam, têm realizado um trabalho da maior importância, atuando não só como órgãos de assessoria e também como entidades com gran. des responsabilidades de natureza operacional. O vultoso acervo de relatórios, monografias, publicações periódicas, boletins estatísticos e outros inúmeros trabalhos técnicos e científicos editados por essas Comissões Regionais constituem rico manancial de informações, indispensável não só à pesquisa como à ação prática dos governos e entidades governamentais e privadas que operam nas diversas regióes do globo. No caso específico de nosso continente, a Comissão Econômica para a América Latina, com sede em Santiago do Chile, tem realizado um trabalho do mais alto valor técnico, para o conhecimento dos recursos do continente, de seus problemas econômicos e dos requisitos necessários pa. ra a integração das respectivas economias.

Iniciativa relevante contida na Carta das Nações Unidas foi corporificada em seu artigo 57, no qual se previu que "as várias agências especializadas estabelecidas por acordo intergoverna. mental e possuindo largas responsabilidades internacionais, como tais definidas em seus instrumentos básicos, no campo econômico, social, cultural, educacional, sanitário e correlatos, seriam pos. tas em relação com as Nações Unidas." A essas agências especia. lizadas têm sido atribuídas as mais relevantes funções e as mais altas responsabilidades no campo da cooperação econômica e financeira internacional. Têm elas correspondido de forma satisfa. tória ao pensamento dos elaboradores da Carta das Nações Unidas, que acreditavam, com razão, que a cooperação internacional no campo econômico e social somente se tornaria efetiva se fosse conduzida por entidades especializadas, dotadas da faculdade de agir com autonomia, embora sob a coordenação imediata do Con. selho Econômico e Social e supervisão da Assembléia Geral.

Apesar da diversidade de seus objetivos, as agências especializadas têm certos padrões comuns de organização e sistemas semelhantes de deliberação e operação. Todas elas promovem uma assembléia geral, na qual os seus membros se fazem repre. funcara e se elege uma diretoria ou conselho executivo, com a bléía geral e de por em execução as deliberações desta última. 
Cada uma dessas agências possui uma secretaria permanente sob a direção de um diretor-geral e algumas mantêm comissões ou organismos regionais funcionando em diversos países do mundo. Algumas dessas agências já funcionavam antes da criação da Organização das Nações Unidas, outras se encontravam em fase de organização por ocasião da II Guerra Mundial e outras foram o fruto da iniciativa da ONU. Entre esssas agências internacionais cabe enumerar : a Organização Internacional do Trabalho (OIT); a Or. ganização de Alimentação e Agricultura (FAO); a Organização de Educação, Ciência e Cultura das Nações Unidas (UNESCO); 0 Banco Internacional para a Reconstrçução e o Desenvolvimento (BIRD); o Fundo Monetário Internacional (IMF); a Organização Mundial da Saúde (OMS); a Associação Internacional de Desenvolvimento (IDA); e a Corporação Financeira Internacional (IFC).

Para maior facilidade desta exposição e possibilitar nossa concentração exclusivamente na atuação da ONU no campo econômico e financeiro, especialmente neste último, evitando que a nossa atenção seja dispersada para outros setores que sem dúvida merecem um enfoque especializado fora de nossa competência profissional, vamos examinar a atuação da Organização das $\mathrm{Na}$ ções Unidas em três ramos ou problemas específicos que se fizeram sentir com particular intensidade no após guerra: a) reconstrução econômica das áreas devastadas pela guerra; b) assistência técnica; c) estabilidade nas relações financeiras internacionais; d) financiamento do desenvolvimento econômico; e) comércio internacional.

\section{RECONSTRUÇÃO DAS ÁREAS DEVASTADAS PELA GUERRA}

O mais urgente problema com que se defrontava a ONU, logo após sua criação, era o da reconstrução das enormes áreas do globo devastadas e arruinadas pela conflagração que assolou o mundo de 1939 a 1945 e de devolução à população dessas áreas de condições mínimas de sobrevivência e subsistência. Desde 1943, quando a luta na Europa aproximava-se de seu término, fora instituída a "Administração das Nações Unidas para o Socorro e a Reabilitação (UNRRA)", criada em novembro daquele ano em virtude de acordo assinado por 44 nações para a execução de um amplo programa de amparo às vítimas da Guerra. A UNRRA concentrou suas operações na prestação de assistência às nações mais devastadas pelas operações militares e que não se encontra. vam em condições de financiar com seus próprios recursos seus programas de recuperação. A UNRRA exerceu sua atividade em 25 paises e atendeu a mais de 1 bilhão de pessoas no fornecimen-

R. Serv. públ., Brasilia, 109 (1) Jan./mar. 1974 
to de alimentos, roupa, combustível, abrigo, medicamentos, assistência através de pessoal habilitado, bem como na concessão de equipamento industrial e agrícola para auxiliar a recuperação econômica das áreas devastadas. A organização tomou também a seu cargo a criação de campos destinados à repatriação de milhões de deslocados pela guerra. Todos os países membros das Nações Unidas que não tinham sido invadidos durante a guerra contribuiram para as despesas da UNRRA com importância equivalente a $1 \%$ do respectivo produto nacional estimado para o ano fiscal de 1943. Com esses recursos foi possivel enviar para as áreas mais devastadas pela guerra 25.000 .000 de toneladas de abastecimento avaliadas em 4 bilhões de dólares. A UNRRA encerrou suas atividades em 1947, transferindo seus projetos em execução a outras agências instituídas pela ONU: a Organização Internacional de Refugiados; o Fundo Infantil de Emergência das Nações Unidas (UNICEF); e a Organização Mundial da Saúde.

Por ocasião da guerra da Coréia, a Assembléia Geral da ONU criou uma "Agência Coreana de Reconstrução" a fim de fazer face aos danos e devastações causados por aquela guerra na região (Coréia do Sul) onde foi autorizado o acesso e permitida a ação dos agentes das Nações Unidas.

\section{ASSISTÊNCIA TÉCNICA}

Uma instituição do tipo das Nações Unidas, da qual participam, ao lado das nações mais atrasadas e daquelas em estágio de desenvolvimento, as nações mais adiantadas do mundo nos diversos ramos da ciência e da tecnologia, tem condições excepcionais para a prestação de uma assistência técnica efetiva, principalmen. te aos países que necessitam desesperadamente da importação de "know-how" como elemento imprescindivel para a aceleração de seu progresso econômico e social. Por esse motivo, um modesto programa de assistência técnica aos países menos adiantados foi instituído em 1946, quando a Assembléia Geral aprovou uma reso. lução determinando ao Secretariado o estabelecimento da maquinária necessária para o fornecimento dessa ajuda. A Assembléia Geral de 1949 aprovou um Plano Ampliado de Assistência Técnica a ser mantido através da contribuição voluntária dos Estados-mem. bros. A partir de 1965 a dotação orçamentária anual para a Assis. tência Técnica tem superado 50 milhões de dólares, com a aplica. ção destinada principalmente à produção agrícola; pesquisa de re. cursos básicos; serviços de saúde e de educação. Uma das mais interessantes modalidades da assistência técnica da ONU tem consistido na concessão de milhares de bolsas de estudo nos 
mais variados ramos do conhecimento e o envio de inúmeros es. pecialistas aos países que os solicitam.

\section{ESTABILIDADE NAS RELAÇÕES FINANCEIRAS INTERNACIONAIS}

Preocupados com a restauração financeira do mundo no após guerra, reuniram-se em 1944, em Bretton Woods, nos Estados Unidos, em uma Conferência Financeira e Monetária Internacio. nal, representantes de 44 países, unidos no objetivo comum de promover a cooperação monetária internacional, sem todavia esta. belecer recomendações que manietassem a ação dos diversos governos dentro do quadro de rígidas e estáveis taxas de conver. são. Sabiam também os especialistas reunidos em Bretton Woods que seria impossível conseguir a adoção universal de taxas livres de câmbio ou eliminar totalmente os controles governamentais sobre o comércio e as transações financeiras internacionais.

Dessa reunião surgiram o Banco Internacional para a Recons. trução e o Desenvolvimento e o Fundo Monetário Internacional, constituídos efetivamente em 1946 e que iniciaram suas opera. ções em 1947.

O Fundo Monetário Internacional foi constituído, não só com o objetivo de promover a cooperação monetária internacio. nal, como também para facilitar a expansão e o crescimento equilibrado do comércio multilateral; promover a estabilidade das taxas de câmbio, evitando depreciações cambiais de caráter competitivo; prestar assistência aos países membros para o estabelecimento de maior liberdade nos pagamentos internacionais e livre conversibilidade em suas contas correntes internacionais sem medidas comerciais de caráter discriminatório ou restrições cambiais; e, finalmente, reunir fundos em moedas conversíveis a fim de torná-los disponíveis aos países-membros do Fundo.

Para a constituição do Fundo estabeleceu-se para cada paísmembro a obrigação de subscrever uma quota, parte em ouro, parte na moeda do próprio país. Para cumprir sua finalidade de promover a estabilidade das taxas de câmbio e assistir os paísesmembros quando os mesmos se defrontarem com dificuldades temporárias em seus balanços de pagamento, o Fundo não só lhes presta orientação e assistência técnica como lhes permite adquirir, mediante pagamento em sua própria moeda nacional, o ouro ou a moeda conversível de que necessitam. Essa aquisição, em princípio, deve ser limitada anualmente a $25 \%$ da quota que o país interessado tenha subscrito no Fundo, não podendo o total das compras exceder a $125 \%$ do valor da quota. Têm ainda os países. 
membros a possibilidade de obter do Fundo créditos "standby" a serem por eles usados se e quando necessários.

A condição de participante do Fundo impõe aos paísesmembros certas restrições, tais como não alterar o valor de sua unidade monetária sem prévia concordância do Fundo; fazer esforcos para eliminar os controles cambiais e as taxas múltiplas de câmbio; bem como consultar anualmente o Fundo a fim de obter do mesmo assistência e orientação visando a consecução de es. tabilidade monetária e a liberação das transações de câmbio.

Apesar da crença generalizada em sentido contrário, o Fundo Monetário Internacional não tem poder algum para ditar normas de caráter monetário a qualquer dos países-membros. Suprindo esses países com a assistência técnica pelos mesmos solicitada e facilitando-Ihes a aquisição, quando necessária e em situações de emergência, de moeda conversível, consegue o Fundo evitar ou moderar crises cambiais e diminuir a instabilidade das moedas nacionais.

Durante a primeira década de sua existência, o Fundo Monetário Internacional não se mostrou muito ativo, consistindo a maioria de suas transações na concessão de empréstimos em dólares americanos aos países em desenvolvimento. Todavia, no fim da década dos 50 , com a recuperação da Europa e a rápida expansão do comércio e dos investimentos internacionais, o Fun. do ampliou suas operações, assistindo com os melhores resulta. dos, diversos de seus países-membros, incluive o Canadá, a Itália € a Inglaterra a enfrentarem graves crises monetárias. Simultaneamente, o número de países-membros do Fundo cresceu rapida. mente e a quota dos países-membros teve de ser acrescida.

O Fundo Monetário Internacional é governado por uma Assembléia de Governadores, que se reune anualmente e é integra. do pelos Ministros da Fazenda ou das Finanças dos países-mem. bros. Uma Diretoria Executiva, composta de 20 membros, 5 dos quais representam os países que subscreveram as 5 maiores quotas do Fundo e os 15 restantes são eleitos pela Assembléia dos Governadores, administra os negócios do Fundo.

A estreita e contínua ligação entre o Fundo Monetário In. ternacional e os países-membros tornou o Fundo um efetivo ins. trumento de cooperação internacional e um notável centro de pesquisas, de estatísticas e de informações sobre economia monetá. ria internacional. Outrossim, para facilitar os países-membros a utilização de suas quotas para enfrentar dificuldades temporárias 
em seus balanços de pagamento, novos e efetivos instrumentos de ação foram criados, entre os quais se destacam o "Sistema para Empréstimos Standby", o "Sistema Geral de Empréstimos" e o "Financiamento Compensatório para Flutuações nas Exportações".

O "Sistema de Empréstimo Standby", introduzido em 1945, possibilita aos países-membros negociarem empréstimos como antecipação de futuras necessidades de moedas conversíveis e temse mostrado de grande valia quando expectativas de dificuldades financeiras podem dar lugar a manobras especulativas. O Brasil tem-se utilizado freqüentemente do "Sistema de Empréstimos Standby".

O "Sistema Geral de Empréstimos", instituído em 1961, por um Grupo de 10 países participantes do Fundo, principalmente paises europeus, teve por finalidade instituir recursos especiais, até o limite de 6 bilhões de dólares, por eles fornecidos, para assisti-los em eventuais e temporárias dificuldades em seus balanços de pagamento. A Inglaterra utilizou-se largamente do sistema por ocasião das crises sofridas pela libra esterlina.

O "Financiamento Compensatório para Flutuações nas Exportações", introduzido em 1963, tem o objetivo de habilitar os países em estágio de desenvolvimento a fazer face a quedas repentinas em suas receitas de exportação, sem que se vejam obrigados a estabelecer severas restrições cambiais ou se sujeitarem a uma deflação aguda.

Para melhor atingir suas finalidades, o Fundo Monetário Internacional instituiu os "Direitos Especiais de Saque", cuja criação foi decidida, em princípio, na Assembléia dos Governadores realizada em 1967 no Rio de Janeiro. A crescente demanda de reservas conversíveis, conseqüente às sucessivas crises financeiras que abalaram as moedas de diversos países, inclusive o dólar americano, determinou a criação do novo sistema que consistiu, na realidade, em ampliar os direitos de saque sobre o Fundo por parte dos países-membros. Em 1972, o Fundo Monetário Internacional constituiu um "Comitê da Junta de Governadores para a Reforma do Sistema Monetário Internacional e Questões Afins". Esse Comitê é integrado por 20 membros, cinco dos quais são indicados pelos países com direito à nomeação de um Diretor Executivo (Estados Unidos, Grã-Bretanha, França, Alemanha e Japão) e os demais pelos quinze países que elegem os Diretores restantes. 


\section{FINANCIAMENTO DO DESENVOLVIMENTO ECONOMMICO}

A Conferência Financeira e Monetária Internacional, reunida em Bretton Woods em 1943 e da qual resultou a criação do Fundo Monetário Internacional, instituiu, também, um Banco Internacional para a Reconstrução e o Desenvolvimento, conhecido igualmente como Banco Mundial, constituído como uma agência internacional destinada a auxiliar o financiamento de projetos sadios para a reconstrução das áreas devastadas pela guerra, assim como para o desenvolvimento dos recursos econômicos mundiais, particularmente nas áreas subdesenvolvidas.

Os Estatutos do Banco, aprovados em 1945, fixavam os três objetivos seguintes :

1) Prestar assistência à reconstrução e ao desenvolvimento dos países-membros, facilitando-lhes a obtenção de investimentos de capital para fins produtivos e, dessa forma promovendo o crescimento a longo prazo do comércio internacional e a melhoria dos padrões de vida.

2) Promover o investimento privado estrangeiro pela concessão de garantias e participação em empréstimos e em outros investimentos feitos por investidores privados.

3) Quando o capital privado não for disponível em condições razoáveis, fazer empréstimos para fins produtivos com os seus próprios recursos ou utilizando fundos obtidos por empréstimo para esse fim.

O Banco Mundial, que tem sua sede em Washington e iniciou suas atividades em 1946, pode realizar as seguintes operaÇões :

a) emprestar dinheiro diretamente, seja utilizando os recursos de seu próprio capital, seja utilizando os fundos que obtiver por empréstimos nos mercados financeiros privados; b) dar sua garantia a empréstimos feitos por terceiros; c) participar em empréstimos feitos por terceiros. Os empréstimos podem ser feitos diretamente aos países-membros, a suas subdivisões políticas assim como a empresas comerciais ou agrícolas privadas estabelecidas nos países-membros. Quando o país-membro em cujo território é localizado o projeto financiado não é o próprio prestamista, esse país, seu Banco Central ou outra agência aceita pelo Banco Internacional deverá dar sua garantia à operação.

As primeiras operações do Banco Mundial, iniciadas em 1946, visaram a execução de projetos ligados à reconstrução de 
diversos países ęuropeus cujas economias tinham sido devastadas pela guerra. A partir de 1949, todavia, o Banco transformou-se principalmente, em fonte de suprimento de capital a longo prazo para os países economicamente atrasados.

O Banco obtém seus recursos não só do capital subscrito pelos países-membros e do lucro das operações que realiza, como também de empréstimos obtidos no mercado mundial de capitais e que constituem, atualmente, a principal origem de seus fundos. O Banco Mundial se especializa no financiamento de grandes projetos a cargo de empresas públicas e privadas e que exigem largas somas de recursos financeiros para sua execução e longo período de amortização da dívida. Concede também o Banco Mundial financiamentos a bancos nacionais de fomento e desenvolvimento, para que estes últimos financiem projetos públicos e privados. Ultimamente, o Banco vem dando especial atenção à concessão de empréstimos para a expansão e melhoramento da agricultura e da pecuária em diversos países, a fim de melhorar as condições de alimentação em todo o mundo. Em princípio, os recursos fornecidos pelo Banco devem ser utilizados exclusivamente para a importação de equipamentos e serviços que não podem ser produzidos no país onde o projeto financiado será executado, podendo esses equipamentos e serviços serem importados de qualquer país-membro do Banco. Só excepcionalmente parte dos recursos provenientes do empréstimo poderá ser aplicada dentro do próprio país em favor do qual é concedido o financiamento.

O Banco Mundial tem se encarregado, também, da prestação de assistência técnica aos países em estágio de desenvolvimento econômico, quer auxiliando-os na elaboração de projetos a serem financiados pelo Banco, quer, como aconteceu no Brasil, enviando missões especializadas a fim de prepararem um levantamento geral dos recursos do país e de suas possibilidades econômicas e formularem recomendações específicas, aos respectivos Governos. Em 1955, o Banco Mundial criou um Instituto de Desenvolvimento Econômico, como um centro de treinamento para funcionários dos países em estágio de desenvolvimento econômico e com responsabilidade na preparação e execução de projetos de desenvolvimento.

Em setembro de 1960, o Banco Mundial criou, como instituição a ele filiada, a Associação Internacional de Desenvolvimento (IDA) com o objetivo de conceder empréstimos aos países economicamente atrasados em condições mais flexíveis e favoráveis do que as estabelecidas pelo próprio Banco. 
Apesar da limitação de seus recursos, obtidos, como vimos, principalmente através do lançamento de títulos no mercado internacional e privado de capitais, sujeitos, portanto, às oscilações e aos custos desses mercados, têm sido expressivos os resultados alcançados pelo Banco para o desenvolvimento econômico e o meIhor aproveitamento dos recursos naturais e humanos das áreas mais atrasadas do globo. Importantíssimos projetos de infra-estrura, em diversos países, têm tido sua execução possibilitada em virtude de terem obtido o apoio financeiro do Banco. O Brasil tem. se utilizado bastante das facilidades oferecidas pelo Banco Mundial, bastando mencionar o fato de ter sido essa instituição internacional que tornou possível o início da execução do projeto de aproveitamento hidroelétrico da Cachoeira de Paulo Afonso, cuja importância foi primordial para a melhoria das condições econômicas do Nordeste Brasileiro. Os empréstimos concedidos pelo BIRD ao Brasil somaram, até 31-12-1972, um total de 1.546 milhões de dólares, destinados principalmente à energia, rodovias e in. dustrialização.

Uma outra instituição afiliada ao Banco Mundial, a Corporação Financeira Internacional (IFC), foi incorporada em 1955, com o objetivo de estimular o desenvolvimento econômico das áreas atrasadas do mundo, através do suprimento de capital de risco para a criação ou expansão de empresas produtivas. A filosofia que predominou na criação da IFC foi a de estimular a formação de empresas privadas de tipo capitalista nos países em estágio de desenvolvimento econômico. Em conseqüência, a IFC nẩo subscreve ações de empresas governamentais ou de sociedades de economia mista nas quais é significante a participação governamental, mas apenas de empresas de capital privado. A sua ação é de caráter supletivo, pois a Corporação somente subscreve ações de uma empresa após a demonstração feita por esta de que nuo The foi possível levantar no mercado privado de capitais a totalidade dos recursos necessários. As ações subscritas pela IFC em uma empresa podem ser por ela transferidas a investidores privados, o que possibilita à Corporação atuar como uma instituição de "underwriting" no campo internacional. O capital subscrito da IFC é de US\$ 107 milhões, cabendo ao Brasil US\$ 1,16 milhão. $O$ Brasil tem sido o principal beneficiário das aplicações da Corporação, seguido pelas Filipinas, México, Índia e lugoslávia.

\section{COMÉRCIO INTERNACIONAL E DESENVOLVIMENTO ECONÔMICO}

A Organização das Nações Unidas, através do seu Consetho Econômico e Social, recebeu sempre reclamação generalizada 
dos países economicamente atrasados, membros da Organização, de que os termos do comércio internacional são-lhe desfavoráveis, uma vez que a tendência decrescente dos preços das matérias-primas por eles exportadas se defronta com uma tendência crescente dos preços dos artigos manufaturados que são obrigados a importar. Em conseqüência, os países econômicamente atrasados lutam com uma tendência crônica para o deficit de seu balanço de pagamentos que supera a assistência financeira recebida das instituições internacionais de crédito.

Atendendo à solicitação das nações menos desenvolvidas, a ONU realizou em Genebra, em 1964, uma Conferência de Comér. cio e Desenvolvimento, na qual os países em estágio de desenvolvimento econômico solicitaram, em bloco, não só a concessão de preferências tarifárias em seu favor por parte das nações mais adiantadas, como a realização de conferências para a estabilização dos preços dos bens primários que constituem os principais itens de suas exportações. A Conferência não chegou a nenhum resultado concreto face à recusa das nações economicamente adiantadas em aceitar as reivindicações formuladas pelos países em estágio de desenvolvimento e que incluiam, não só a elevação dos preços das matérias-primas na mesma proporção do crescimento dos preços dos artigos manufaturados, como a redução dos fretes marítimos e dos juros dos empréstimos internacionais. Ficou, todavia decidida a convocação de outras Conferências Internacionais de Comércio e Desenvolvimento, a instituição de um Conselho Permanente de Comércio e Desenvolvimento, assim como a designação pelo Secretário Geral da ONU de um SecretárioGeral para o Comércio e Desenvolvimento, assistido por um Secretariado permanente, para tratar especificamente dos assuntos relacionados com o comércio internacional e o desenvolvimento econômico das áreas mais atrasadas do mundo.

\section{CONCLUSÕES}

Face à necessidade de limitar sua extensão, este artigo omitiu muitos aspectos importantes da ação das instituições financeiras internacionais ligadas a ONU ou abordou superficialmente questões da maior relevância.

Esperamos, todavia, haver atingido nosso objetivo, que foi o de demonstrar o grande esforço realizado pela Organização das das Nações Unidas no sentido de contribuir, através da melhoria e da ampliação das relações financeiras internacionais, para acelerar o progresso econômico e social das regiões mais atrasadas 
do mundo e apoiar as Nações que executam um grande e permanente esforço para superar o subdesenvolvimento em que ainda se encontram.

A paz mundial e a justiça internacional, os dois grandes objetivos das Nações Unidas, somente podem ser alcançados com a eliminação das áreas do nosso planeta onde ainda imperam o atraso tecnológico, a pobreza, a ignorância e a iniqüidade social. Essa eliminação somente será possível através da colaboração internacional e, principalmente, se contar com a disposição das Nações ricas no sentido de dividerem com as Nações mais atrasadas uma parcela da riqueza e do progresso tecnológico que acumularam. Para a consecução desse objetivo é condição essencial a preservação da Organização das Nações Unidas e o seu crescente prestígio, como única Assembléia onde é permitido o livre e franco debate dos problemas que afligem os povos e as Nações. 


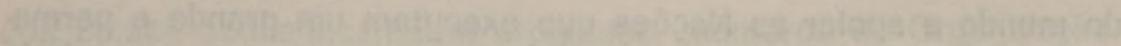

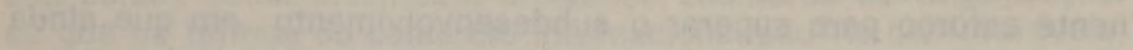

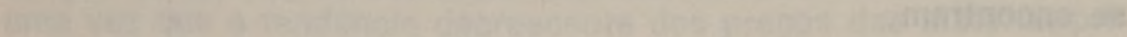

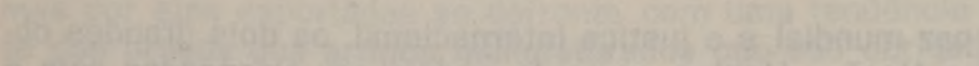

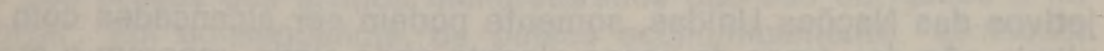

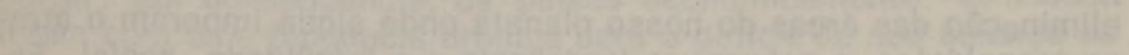

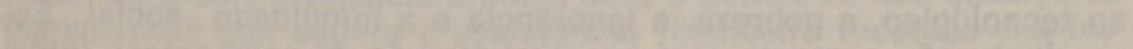

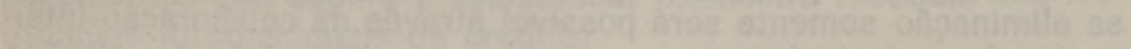

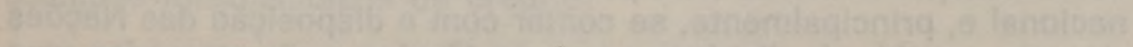

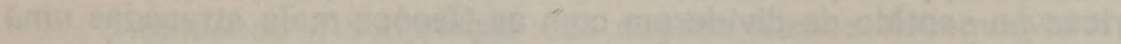

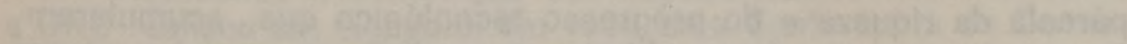

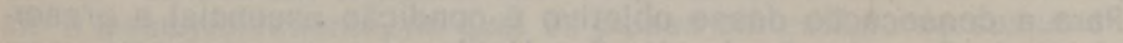

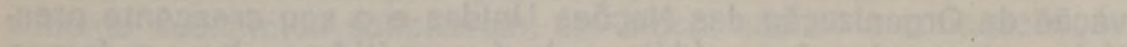

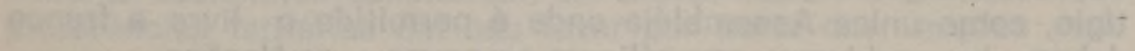

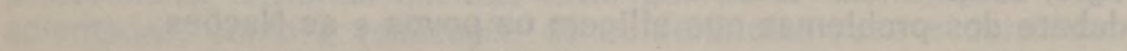

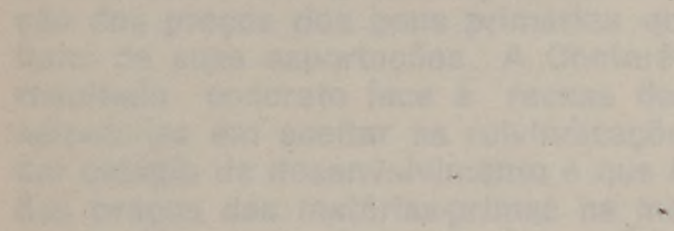

- n- n

2010 -

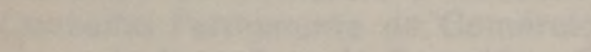

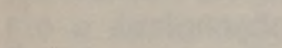

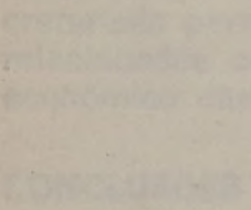

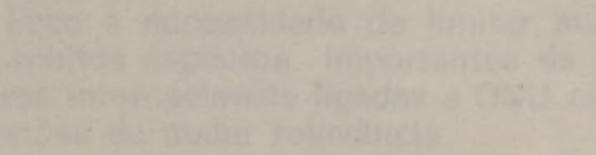

